\title{
Improvement of efficiency of complex treatment of chronic periodontitis based on microbiological research
}

\author{
Khasanova L.E., Najmiddinova N.B. \\ Tashkent State Dental Medical Institute Republik of Uzbekistan
}

Email address:

ayntraxt@gmail.com (Khasanova L.E., Najmiddinova N.B.)

\section{To cite this article:}

Khasanova L.E., Najmiddinova N.B. Improvement of efficiency of complex treatment of chronic periodontitis based on microbiological research. Journal of research in health science. Vol. 2, No. 2, 2017, pp. 48-51. DOI 10.26739/2523-1243

\section{dol http://dx.doi.org/10.26739/2523-1243/-2017-2-2-8}

\begin{abstract}
When analyzing the composition of microorganisms in the teeth after primary and repeated endodontic treatment, it is concluded that the composition is limited to very specific variety of microorganisms, with the predominance of Gram-positive facultative anaerobes. The choice of methods and tools for the treatment of chronic forms of periodontitis remains relevant in therapeutic dentistry. The possibilities of bacteriological diagnostics make it possible to selectively target and use antibacterial drugs in the treatment of chronic apical periodontitis with minimum complications and maximum clinical effect. In this article, comparative analysis of treatment results of patients with chronic apical periodontitis is considered.
\end{abstract}

Keywords: root canal, periodontitis, temporary filling, Metrogil Denta, Lindoxin, periodontopathogenic flora.

\section{INTRODUCTION}

It is known that one of the most important stages in the treatment of destructive forms of chronic periodontitis is the antimicrobial treatment of the root canal system. The leading role of the microflora of the oral cavity in the etiology of chronic forms of periodontitis is proved. The problem in the disinfection of the root canals is intra-channel biofilm.
According to the modern concept, microorganisms in the root canals are present in the form of bacterial biofilm, which makes it difficult to eliminate them from the root canal system [3-5].

Principles of endodontic treatment of chronic forms of apical periodontitis (CFAP) include not only instrumental treatment and obturation of the root canal, but also adequate local medication. 
Many authors believe that in most cases the reason for the unsuccessful treatment of complicated caries is inadequate, insufficient drug treatment of the root canals [4]. In addition, the researchers prove that even in the presence of extensive periapical changes, the bacteria in the overwhelming majority are in the root canal system, and behind the tip of the root are found rarely and in small amounts, usually with exacerbation of chronic periodontitis $[3,7,8]$.

Temporary filling of the root canals with Metrogil Denta pasta is an effective method of treating chronic forms of apical periodontitis, since it has a prolonged antibacterial effect on the root canal system [4, 7].

Given the localization of the inflammatory process with apical periodontitis, a great interest is the study of the immunological parameters of the tissue surrounding the pathological focus. It is established that the most informative for this pathology are the indices of local immunity, especially its separate link in the region of the tooth-jaw segment of the causative tooth [6].

The aim of the study is to study therapeutic paste in the treatment of patients with chronic apical periodontitis on the basis of microbiological studies.

\section{MATERIALS AND METHODS}

To solve the set goal, we conducted a survey and treatment of 60 patients with chronic forms of apical periodontitis, in which 68 teeth were cured. Of the 68 teeth, 33 (44.5\%) were single-rooted, 35 $(55.5 \%)$ were multi-rooted.

For microbiological studies in patients with chronic periodontitis, material was taken from the root canals of the teeth using a sterile endodontic paper pin of size 25 , which was then placed in a transport system (semi-liquid Amie's nutrient medium) and stored at 2-4 ${ }^{\circ} \mathrm{C}$ until further culture. Samples of the test material from the root canals were delivered to the bacteriological laboratory for 1 day.

The study included quantitative sectoral seeding on media designed to cultivate oral bacteria in aerobic and anaerobic conditions. Pure cultures of obligateanaerobic and microaerophilic bacteria were obtained under anaerobic conditions. The crops were incubated in anaerostat with an oxygen-free gas mixture containing $80 \%$ nitrogen, $10 \%$ hydrogen. $10 \%$ carbon dioxide for 3-5 days.

Identification of microorganisms and assessment of the sensitivity of isolated strains of virulent bacteria to antibiotics was carried out with the help of the automated system "Autoscan" (Siemens).

Therapy of patients with chronic apical periodontitis consisted in the medicamentous treatment of the root canals and in a temporary investment for 10 days of medications with subsequent permanent filling.

Depending on the drug used, patients were divided into two groups. In the first main group, $3 \%$ sodium hypochloride was used to treat the root canal, and for the temporary filling of the root canal, we used calcium hydroxide. In the second main group, Lindoxin was used to treat the root canal, and for the temporary filling of the root canal, we used Metrogil denta professional and also calcium hydroxide. Also, a control group of 15 teeth with a similar pathology was used, which were treated by the traditional method without temporary root obturation.

Treatment of patients with chronic apical periodontitis was carried out according to the protocol of endodontic treatment. 
Khasanova L.E., Najmiddinova N.B. Improvement of efficiency of complex treatment of chronic periodontitis based on microbiological research.

Before the start of treatment and after a temporary injection 10 days later, the patients were re-sampled the contents of the root canal for microbiological evaluation.

In the main clinical groups, after endodontic preparation, temporary filling with calcium-containing preparations for a temporary seal of glass ionomer cement for 1 week, repeated obturation of the root canal with calcium-containing material for a period of 2 weeks (with a general expiration period of 3 weeks) was performed. Then, the root canal system was permanently sealed by lateral condensation of gutta-percha using endomethasone (Septo-dont) as the sealer. The quality of filling and the level of filling of the root canal were performed radiologically.

In patients of the control group, after root canal treatment, the root canals were filled with gutta-percha pins by lateral condensation. All patients were informed of endodontic treatment and agreed.

\section{RESULTS}

In the culture of the contents of the root canal system, associations of different bacterial species (from 1 to 4 species) with high frequency (more than $50 \%$ ) were isolated from each patient, mainly gram-positive flora was isolated from the material studied: the most aggressive types of pathogenic bacteria and saprophytes, hemolytic streptococci were largely met.

The results of sowing from the root canal system, after 10 days, show that the author's paste from components of calcium hydroxide, Metrogylenta, Lindoxin, has the most significant effect against gram-positive and gram-negative microflora. In antibioticograms, there was a significant suppression of the growth of Enterococcus faecalis and Streptococcus mutans, the most representative representatives of periodontogenic flora. The combined use of calcium hydroxide, Metrogyl Denta, Lindoxin, previously not used in dentistry, significantly increases the antimicrobial activity of the paste, increases the anti-inflammatory effect, increases the effectiveness of the treatment of chronic forms of periodontitis, reduces side effects.

The use of "Lindoxin" completely suppresses the growth of Staphylococcus epidermidis, which is most typical for patients who have a history of repeated antibiotic treatment or their frequent self-administration. However, this composition shows a low suppression of bacteria of the genus Stapylococcus epidermidis.

The microbiological studies carried out made it possible to analyze the efficacy of various drugs on the periodontopathogenic flora and to justify the choice of means and techniques for the treatment of chronic apical periodontitis.

\section{CONCLUSIONS}

Analyzing the results of approbation, it can be concluded that the proposed paste for temporary filling of the root canal of the calcium hydroxide component, Metrogylenta, Lindoxin, is convenient for use, well tolerated by patients, has no side effects and contraindications to use. The data obtained make it possible to recommend the proposed paste for effective treatment in chronic forms of periodontitis, both with regard to the dosage and the time of its exposure, as confirmed by specific clinical examples. 
Thus, the results of the conducted microbiological research give grounds to recommend the preparations "Lindoxin" and "Metrogyl denta" for wider use in the treatment of chronic forms of apical periodontitis, in comparison with the traditional treatment regimen.

\section{REFERENCES}

[1] Clinical study of the efficacy of chronic apical periodontitis treatment. Ivanchenko [and others] // Russian Dental Journal, 2008.- No. 5.- P. 33-36.

[2] Treatment of apical periodontitis: Proc. allowance / N.N. Trigolos [and others]; Ed. V.F. Michalchenko; VolgGMU.- Volgograd: VolgGMU publishing house, 2011.- 84 p.

[3] Therapeutic dentistry: the national leadership / ed.L.A. Dmitrieva, Yu.M. Maksimovsky .Moscow: GEOTAR-Media, 2009.-912 p.

[4] Leonova LE, Kolomiytsev VF, Cherepanov A.Yu. Features of the general and local phagocytic reaction neutrophils in patients with chronic apical periodontitis. Proceedings of the XXIII and XXIV All-Russian Scientific Conferences. M .: OOO Dental, 2010. P. 44-47.

[5] Mitronin AV, Tsarev V.N. Clinico-microbiological evaluation of the effectiveness of endocanal use of the bioactive gel Collapse in the treatment of chronic periodontitis // New in Dentistry. 2004. № 5. P. 50-60.

[6] Baron A., Lindsey K., Sidow S.J., Dickinson D. et al. Effect of a Benzalkonium Chloride Surfactant-Sodium Hypochlorite Combination on Elimination of Enterococcus faecalis // Journal of Endodontics. 2016. Vol. 42, Issue 1. P. 145-149.

[7] Gongalves L.S., Rodrigues R.C., Andrade Jr. C.V., et al. The Effect of Sodium Hypochlorite and Chlorhexidine as Irrigant Solutions for Root Canal Disinfection: A Systematic Review of Clinical Trials // Journal of Endodontics. 2016. Vol. 42, Issue 4. P. 527-532.

[8] Pladisai P., Ampornaramveth R.S., Chivatkharanu- kul P., Clin Sci G.D. Effectiveness of Different Disinfection Protocols on the Reduction of Bacteria in Enterococcus faecalis Biofilm in Teeth with Large Root Canals // Journal of Endodontics. 2016. Vol. 42, Issue 3. P. 460-464. 